Kally WHITEHEAD

Tim KURZ

School of Psychology, Murdoch University

'Empowerment' and the pole: a discursive investigation of the re-invention of pole dancing as a recreational activity

The activity of 'pole dancing' has recently been transformed from an act performed exclusively in strip clubs to one currently marketed as a form of aerobic exercise. While much feminist academic work has investigated aspects of the sex industry, such as stripping, very little research has been conducted into this recent social phenomenon of pole dancing as a recreational activity. This study takes a feminist poststructuralist approach to the investigation of this topic through the discursive analysis of talk produced in a range of focus groups and interviews. Participants included instructors at pole dancing studios, regular pupils at the studios, once-off pole dancers, and general university students (a total of 25 participants; 20 females and 5 males). Our analysis focuses on the ways in which ideological dilemmas surrounding issues such as empowerment, control, and the male gaze are managed within the participants' accounts. Implications of these constructions are discussed in relation to the redefinition/reiteration of hegemonic, patriarchal notions of female sexuality.

Keywords: Pole dancing; Raunch Culture; Discourse Analysis; Female Sexuality 
The theorizing of female agency within the so-called post-feminist society has been a topic of some debate within recent feminist scholarship. Much of this debate has centered around the issue of how feminist scholars might conceptualize and respond to what Gill (forthcoming) has referred to as the 'supersexualizing' of female bodies within the mainstream media in recent years, and society more broadly. A key element of the construction of this 'new' female sexuality has been the extent to which it is represented (for example, in advertising) as powerful and playful, as opposed to the passive or victimized object of the male gaze. Concurrent with such changes in media representations has been the rise of what McNair (2002) has referred to as 'porno chic', namely, the increasing infiltration of images, clothing, and activities that were previously the exclusive domain of the pornography industry into the mainstream. In this context, debate has emerged within the field regarding the appropriate ways to theorize female agency in the context of these developments, as exemplified in the recent exchange between Duits and van Zoonen (2006) and Gill (2007) in the pages of the European Journal of Women's Studies. Is one to conceptualize the various choices of women to wear items such as g-strings and playboy bunny midriff tops in terms of empowered women making free, autonomous choices? And if so, should the voices of these women not be fore-grounded and respected, rather than critiqued and problematized? Alternatively, one may question whether 'giving voice' to individual experience may consequently preclude a recognition and analysis of the pervasive cultural contexts constraining choices around issues such as dieting, cosmetics and plastic surgery (for examples, see Davis, 1995; Duits and van Zoonen, 2006; Gill, 2007; Scott, 2005). Indeed, the tensions that arise between 'giving voice' to participants verses critical cultural 
analysis of wider socio-cultural issues have long been a concern within feminist research (Weatherall, Gavey \& Potts, 2002).

The research project outlined in the current paper brings these debates around female agency to bear on the current social phenomenon of 'recreational' pole dancing classes that are offered to women. Whilst much academic research has focused on the arena of professional stripping, and the sex industry in general, very little research has, to date, focused directly upon pole dancing as a mainstream activity marketed to women as an exercise alternative. In the current project, we explore what we term 'recreational pole dancing' through an analysis of talk produced around the topic. This talk is produced by groups of people with a variety of different experiences related to recreational pole dancing and who differ with regards to their 'stake' in the issue. Rhetoric around pole dancing is considered within the contexts of female sexuality, the 'pornographication of the mainstream', 'raunch culture', the politics of choice and the idea of power as a constantly renegotiated resource. In doing so, we wish to demonstrate the ways in which such issues are potentially relevant to the analysis of pole dancing, and discuss the implications of this cultural phenomenon in relation to the experience and (de)construction of feminine sexuality. We approach our work from a constructionist epistemology that utilises a feminist poststructuralist perspective (Gavey, 1989; 2005) facilitated through a form of discourse analysis that may be characterized as broadly 'Foucauldian' in nature (Wetherell, 1998; Willig, 2001).

\section{Foucault and sexuality}

Foucault argued that sexuality, far from being a timeless and universal expression of human desire, is in actuality actively produced through forms of professional knowledge and 
institutions dedicated to 'speaking' its truth (Foucault, 1978; Lumby, 1997; McNay, 1992). The experience of sexuality, male or female, is therefore not a natural phenomenon but, rather, actively constructed by people who exist in a particular historical moment. Thus, the understanding of the 'female' by both men and women as inherently sexual (MacKinnon, 1989; Mason-Grant, 2004), 'naturally' inferior (Segal, 1998) and as subservient to men (MacKinnon, 1989; Mason-Grant, 2004) is arguably not only a consequence of patriarchy and the privileging of the 'masculine' as normative. It is also an ongoing negotiation of power between both men and women, with this negotiation occurring within the dominant ideology of patriarchy, which includes the privileging of normative masculinity. Thus, it is arguable that women, as active participants in this negotiation, may participate in their own subjugation (Coward, 1993; Griffin, 1989; Peace, 2003; Whelehan, 1995; 2000), albeit in a social environment in which 'choices' and subjectivities are highly constrained by prevailing patriarchal ideologies. This 'participation' is arguably achieved through the acceptance and internalization of hegemonic notions of female sexuality and femininity, with these notions being conceptualized as inextricably bound to concepts of 'natural' inferiority and constructs of the 'female' as inherently sexual. Thus, the current project also has implications for larger feminist debates that locate contemporary female conduct within a politics of freedom, individualism and choice. Here, choice is seen as a 'cherished principal' (Braun, in press) that is widespread within Westernised culture and is theorized as a critically definitive factor in the ways we perceive ourselves (Hughes, 2002; Gill, 2007). Thus, 'choice' is conceptualized as so important as to supersede the influence of culture itself (Braun, in press). As such, the individual decision to participate in any activity that could be argued to be degrading in a more holistic, cultural manner can be re-worked as empowering and desirable through a discourse of choice. However, as argued by Morgan (1991), this re- 
working of 'choice' can often disguise what is actually acquiescence to prevailing social expectations and instances of conformity.

\section{Recreational Pole Dancing}

Let us now, against this backdrop, consider the social object of pole dancing. The activity of 'pole dancing' is one that has existed in contemporary Western culture for at least the last two decades and perhaps longer. Most commentators consider pole dancing to have originated in Vancouver, during the 1970's and 1980's (Deville, 2006; Keller, 2006; Reeve, 2007). Pole dancing is most often viewed as an extension of exotic dancing, with the pole introduced as a prop upon which to perform spins and tricks. Over the past five or six years, however, pole dancing has begun a transition from one being typically regarded as a sexually-oriented activity to one that is currently marketed as a popular form of recreation and aerobic exercise, albeit still within a discourse of 'sexual liberation/empowerment'. For example, the various marketing slogans attached to promotional material for pole dancing studios in the Australian context include 'Strength and femininity', 'Power and beauty' and 'Sex appeal comes from within'. Moreover, many studios also offer special packages for Hens Nights ${ }^{1}$ that offer the opportunity to "learn a few sexy Pole Dancing moves with all your friends" and "take away some saucy skills". In addition, many also offer lap-dancing classes, which are promoted as an opportunity to "learn the art of seduction, a special dance for a special someone".

Recreational pole dancing classes are predominantly a Western cultural phenomenon. Although there is no empirical literature available to support this claim, an online search of the term 'pole dancing' currently returns (at the time of writing) results primarily from the U.K., Canada, the U.S.A., Australia and Europe. 
As part of the current research project, the first author took three recreational pole dancing classes to gain an insight into what they entailed, at least in the context of this particular pole dancing studio. The sessions can be described as highly comparable to attending an aerobics class at a gym, albeit with certain unique differences. Some classes are aimed at reducing fat, some at improving cardiovascular endurance, some at building muscle and strength with a few 'advanced' classes aimed at improving general agility and mastering more difficult maneuvers on the pole. The clothing worn at this particular studio tended towards 'athletic' wear, that is, designed for a wide range of movement and sweating. Once the class begins, each woman (there were no males allowed on premises in this studio) chooses a pole in a room with approximately 25 individual poles. When the class starts, the lights are dimmed, the music starts and a glitter ball is activated. Participants in the class then follow the instructor's lead in performing maneuvers on their own pole, in a similar fashion to an aerobics class.

One could suggest that the performance of a pole dance in the context of a strip club could be conceptualized as a form of pornography, that is, as something being solely intended to arouse sexual interest (McNair, 2002; Schauer, 2005). When taken out of this context, however, and into the recreational pole dancing studio, it perhaps becomes difficult to label this 'recreational' form of pole dancing as 'pornographic', in the most technical sense of the word. Although recreational pole dancing does not depict the physical act of sex (or aspects of it) with the sole intention to arouse a viewer (Gard, 2003; Murphy, 2003), it is still an act that is (arguably) inherently 'performative' in a way that certain other forms of exercise (such as lifting weights at a gym or jogging around the park) are not. For example, neither jogging nor lifting weights are typically marketed to women as a skill that they can 'show off' (and this arguably even holds for more 'class based' exercise activities such as aerobics). Pole dancing is also 
potentially bound to a subculture in which men enter specified clubs with the intention of watching women display their bodies, possibly with the purpose of achieving arousal (Murphy, 2003). Thus, some could argue that that pole dancing, per se, positions the female body (at least ideologically) as a sexual commodity to be viewed and consumed, most traditionally by men (Levy, 2005; Murphy, 2003).

\section{Recreational Pole Dancing and 'Raunch Culture'}

There have been many cultural trends and 'fads' for women's health and exercise over the past few decades including activities such as aerobics, kickboxing and Pilates. None of these activities, however, have been claimed to be both 'personally empowering' and 'sexually liberating', as is the case for pole dancing. The popularity of pole dancing for recreation at this time can perhaps be best viewed as a consequence of several recent cultural and historical trends. These include what McNair (2002) has labeled 'the pornographication of the mainstream' (pg. 61). As alluded to earlier, this is best described as the movement of pornography from being something of an 'underground activity' to a more culturally pervasive, acceptable and increasingly mainstream social artifact. This movement is thought to have been facilitated by the emergence of 'porno-chic' and 'striptease culture' during the early 1990's (McNair, 2002). Whilst the objectification and sexualisation of the female body is certainly not a new cultural phenomenon by any means, the specific ways in which 'supersexualised' (Gill, forthcoming) representations of female sexuality have become mainstreamed in recent decades have been argued to represent a degree of cultural shift towards what Levy (2005) refers to as 'raunch culture'. This 'raunch culture' encapsulates the cultural trend in popular fashion towards the pornographic and also incorporates the assertion that it is no longer enough for a woman to be 
beautiful or thin to be considered desirable, but must now also be considered sexy and comfortable with an open, exhibitive sexuality. Empirical investigations into examples of activities that could be considered 'porno-chic' or 'raunch' have included studies of young women's participation in the notorious Girls Gone Wild television productions (Pitcher, 2006) and sex toy parties (Attwood, 2005).

We posit that these cultural events are important, not only when considering why pole dancing is currently popular, but also in relation to current societal constructions of female sexuality. As noted by Braun \& Gavey (1999), sexuality is often publicly and pervasively controlled and constructed in Western culture by the media, through its shaping of ideas about normative sexuality. Additionally, McNair (2002) argues that the move towards porno-chic has been informed by, and publicly identified with, feminist ideas (although not necessarily 'Feminism'). These movements also announced the arrival of a new phase of western sexual culture and a new model of femininity in which an open attitude towards sex (and pornography) was considered 'sexy', 'cool', and most importantly, 'sexually liberated' (McNair, 2002). Some authors (e.g., Gill, 2008), however, have questioned the extent to which one may sensibly think of this new 'raunch culture' construction of female sexuality as an unproblematic contemporary continuation of the earlier work of the women's movement towards the sexual liberation of women in society. Whilst feminist values, including sexual entitlement, sexual liberation and personal empowerment are incorporated into 'post-feminist' raunch culture, the resulting 'ways of being' (subject positions) made available through this attempt are argued by Levy (2005) to represent an exhibitionist, 'cartoon-like', male-imagined caricature of female sexuality. This 'technology of sexiness' (Gill, 2007, p. 72) is then sold (often as a consumable product) as the only version of female sexuality that is deemed currently acceptable and desirable to women. 
Additionally, it is arguable that the aforementioned feminist values have been slowly and systematically detached from the feminist movement itself. As has been noted by several authors (e.g. Edley \& Wetherell, 2001; Peace, 2003; Renzetti, 1987; Riley, 2001), the discursive redefinition of ideas such as 'equality', 'subordination' and 'liberation' in certain mainstream discourses of 'power femininity' (Lazar, 2006, p. 21) actually serve to invalidate ongoing attempts to challenge pervasive, hegemonic patriarchal power structures.

Thus, we currently reside in a historical and cultural moment whereby the activity of pole dancing (as a way to 'get fit' and 'feel liberated') is potentially able to make available a range of discourses and subject positions to women. The term 'discourse' is, here, used to describe a 'set of statements that construct objects' (Parker, 1994, p. 245). One can think of discourses as being ways of talking about a topic or concept that a culture makes available to its members, and which make available subject positions (Parker, 1994), with subject positions incorporating both a conceptual repertoire and a location for persons within the structure of rights for those that use that repertoire (Davies \& Harre, 1990). That is, ways of talking about things (discourses) create different opportunities for individual ways of 'being' or experiencing the social world that may differ between different sectors of society. Through the invocation, in talk, of these new discourses of 'raunch' and the resulting available subject positions that are created, women are potentially able to experience and talk about their sexuality in a manner that was not necessarily available prior to the emergence of discourses of female sexuality as assertive, exhibitive and interested in gratification of the self. As outlined by McNair (2002) and Levy (2005), the current cultural climate positions an exhibitive, assertive female sexuality as highly desirable. Thus, pole dancing could potentially be represented as a highly desirable exercise/recreational alternative at this historical and cultural moment. Indeed, as has been noted by Dentith (2004), women who 
seek out activities such as pole dancing, or even work professionally as strippers, are often venerated (in some circles at least) as the 'new' liberated woman. It is argued that proof of 'true' women's liberation is evidenced by the fact that diverse occupations, such as stripping or professional pole dancing, are now accepted and often granted 'star-like' status. This is argued to provide a less denigrated status for women who work in the sex industry. Thus, some may argue that this is, to an extent, 'proof' of the success of feminism and a certain attainment of women's rights. Conversely, however, it may be argued that this is a particular form of feminism that affirms and sustains itself only within the limits of a certain, hegemonic liberal version. What is obscured within such a version is the extent to which liberation experienced on an individual level may often actually secure oppression in covert ways and reinforce public practices that sustain subordination (Dentith, 2004).

Thus, the current re-branding of pole dancing as a recreational activity for women represents a potentially complex ideological dilemma. On the one hand, this process could be conceptualized as representing a form of 'reclaiming', by women, of an activity previously bound to the patriarchal, objectifying, social institution of the strip club. Thus, by relocating the activity in a female-only environment that is devoid of the male gaze, one could argue that recreational pole dancing studios are creating a space in which women can challenge traditional representations of female sexuality as passive and subservient to men. On the other hand, however, one could argue that pole dancing is 'inherently' denigrating and disempowering to women, and that its connection to patriarchal institutions may render its enactment problematic in any context, from a feminist perspective. Thus, pole dancing could arguably be seen to seal particular constructions of gender and sexuality that ultimately fail to disrupt power distribution within society at large. 


\section{Aims of the present study}

The current research aims to investigate the ways in which cultural members construct and manage this potential ideological dilemma in their talk about pole dancing as a 'mainstream' recreational activity. We also wish to consider the potential implications of such constructions for cultural expectations of female sexuality. In particular, our analysis aims to stimulate debate around the issue of whether pole dancing can be seen as opening up new ways of talking (discourses) and ways of being (subject positions) that move away from hegemonic, patriarchal notions of feminine sexuality. With this aim in mind, we investigate how the activity of pole dancing is constructed in the talk of a variety of different groups, each of which had a slightly different relationship with the activity. In doing so, our intention is not to disrespect or ironize our participants' accounts in any way. Rather, we wish to engage with their accounts using what Gill (2007b) has referred to as a 'critical respect' (p. 78).

\section{METHOD}

\section{Participants}

Qualitative data from different types of focus groups and semi-structured interviews were collected, in an attempt to assemble a wide variety of talk. This involved a) two semi-structured interviews conducted with pole dancing instructors who design and teach pole dancing classes at a studio located in a major Australian city; b) one focus group conducted with women who are regular attendees of pole dancing classes at the same pole dancing studio; c) four semi-structured interviews conducted with 'single-occasion' female pole dancers, who may have experienced 
pole dancing in the context of a once-off organized social event such as a Hen's Night ${ }^{1}$ and; d) four focus groups conducted with members of a university undergraduate psychology student population, two of which were composed of women-only group members, and two of which also included men. Our intention was to gain access to a variety of potentially different discursive constructions of pole dancing and female sexuality. We set out to assemble a body of talk that would allow us to analyze some of the complex and nuanced ways in which cultural members might talk about recreational pole dancing and the potential social implications of this.

The information collected consisted of 11 discussion groups/interviews, involving a total of 25 participants, 20 of whom were women. Our participants ranged in age from 18-47 years, with the majority self-identifying as "White Australian". The remaining 6 participants identified as "Burmese Australian”, "Swedish Australian”, "South African Australian”, "Russian Australian” and "Polish" (two) respectively. Whilst demographics relating directly to social class were not collected, the data collected relating to "Occupation" suggest a primarily 'middle class' group of participants.

\section{Procedure}

The focus groups and semi-structured interviews took place at locations that were of convenience to the people participating. The sessions lasted between forty minutes to one hour. All discussion sessions were facilitated by the first author and were guided by a focus group or interview schedule. These schedules consisted of six to eight questions that were designed to elicit responses focusing on female sexuality, pole dancing, empowerment and disempowerment. The discussion sessions began with the moderator/interviewer explaining that the sessions were meant to be an 'informal chat' revolving around the topic of pole dancing. Student focus group 
sessions also utilized stimulus material, which consisted of advertising images that were taken from the websites of two major pole dancing studios in the local area. Although discussion sessions were guided by schedules, they were considered flexible and dynamic discussions where group members largely controlled the direction of conversation.

All sessions were audio-recorded and later transcribed using a simplified version of Jeffersonion notation (Atkinson \& Heritage, 1984). An outline of the specific transcription notation symbols used is provided in the appendix. All participant names that appear in the analysis section are pseudonyms.

\section{Data Analysis}

At the first stage of analysis, any collected talk that was related to the broad topics of sexuality, empowerment, degradation, performance, control, choice, enjoyment, discomfort, power, men, individuality, stereotypes, maturity, culture, the gaze and objectification were included in a first body of instances (Potter \& Wetherell, 1987). From here, the body of instances was revised three times before settling on a final copy. At each revision, the topics of inclusion became more narrow and specific. Finally, the issues considered most pivotal for inclusion in a final body of instances related to sexuality, power and control. At the final revision, three discourses were identified that we believed to be crucial to the discursive construction of pole dancing in the current data corpus. From here the data set was subjected to a Foucauldian form of discourse analysis, as stipulated by Willig (2001). 
In the initial stage of our analysis we were primarily concerned with the ways in which the discursive objects explicitly related to our research question were constructed in the talk we were analyzing. This includes both explicit and implicit references to pole dancing and female sexuality. We then focused on the specific variablities in the constructions of pole dancing and female sexuality in contributors' talk. From here a closer analysis of the discursive contexts within which the different constructions of pole dancing and female sexuality was conducted. We then considered the subject positions that these discursive constructions offered to potential consumers of pole dancing. Next, we systematically explored the ways in which the discursive constructions of pole dancing and the subject positions offered by these constructions open up, or alternatively close down, opportunity for action in regard to female sexuality. Finally, we explored the relationship between discourse and subjectivity, by tracing the consequences of taking up a particular subject position for the consumers' subjective experience (Willig, 2001).

\section{Theoretical Assumptions}

Our theoretical and analytic approach can be best described as being derived from a feminist poststructuralist perspective (Gavey, 1989; 2005). This approach is concerned with the construction of reality and power through language, with that construction being inextricably connected to gendered power relations. Our primary concern is with the ways in which certain conceptions of pole dancing and female sexuality may come to be seen as (particular versions) of 'social reality'. Moreover, our analysis aims to examine the implications that these constructions may have for the social construction of female sexuality more broadly.

\section{ANALYSIS}


We will now analyze the ways in which the activity of pole dancing was constructed by our participants in their talk around the topic. In particular, we wish to focus on the ways in which notions of 'empowerment' and 'degradation' were invoked, managed, and justified within these accounts. We characterize three ways in which the issue of (dis)empowerment was constructed within the talk, with these relating to discourses of (1) fun and fitness; (2) control of money and choice; and (3) performance and the male gaze. We will then discuss how these three discourses construct subject positions around recreational pole dancing with specific reference to female sexuality, power and control.

\section{Fun and/or Fitness as a qualifier for empowerment}

Recreational pole dancing was repeatedly framed within discourses of 'fun' and/or 'fitness'. As demonstrated in the following two extracts, these discourses of fun and fitness often served the rhetorical function of negating, shutting down, or side stepping potential accusations that some may seek to bring against the activity pole dancing, including such arguments as the assertion that it could potentially be a degrading activity for women.

\section{Extract 1: Student Focus Group 2}

630 Alice: $\quad[\mathrm{U}:: \mathrm{m}]($.$) well I think if you're doing it for fitness it can be empowering (.)$ 631 because it's like (.) if you're having fun doing it and you're getting fit at 632 the same time (.) you're gunna (.) you're gunna feel good about [yourself] 633 Interviewer: [Yep]

634 Alice: cos you're like 'oh I'm having fun at this and I'm getting fit at the same time' (.) but I don't think it's always empowering for like (.) the women in the clubs because (0.5) I don't think the men are going to see the women (.) they're going to see their bodies they don't see them as a woman (.) they just see them as something to look at (.) something pretty to see $(\mathrm{h})$ 
The construction of pole dancing as an activity for 'fun and fitness' by Alice in extract 1 serves an important rhetorical function. Alice compares and contrasts recreational and professional pole dancing, stating at different points in the extract that 'I don't think it's always empowering' (line 635, emphasis added) and 'if you're doing it for fitness it can be empowering' (line 630, emphasis added). This serves to construct the act of dancing around a pole as an inherently neutral activity that can be seen as empowering or disempowering, as a function of the specific context of its enactment. In relation to this, contextual qualifiers such as 'having fun' 'getting fit' and hence, feeling 'good about yourself' (line 632) work to characterize recreational pole dancing as empowering. In direct contrast, the participant constructs professional pole dancing as disempowering, on account of the assumed subjective position of the male spectators. Specifically, the male spectator is constructed as seeing 'the body' rather than the 'woman' and as not seeing them as a woman, but rather as an object (line 637). This serves to discursively locate the professional pole dancer as sexually objectified. Thus, the discursively constructed contextual environments of 'fun and fitness' verses 'sexual objectification' work to position pole dancing itself as neutral, with the context within which the behavior is enacted as either empowering or disempowering.

This construction works to negate arguments that may be brought against recreational pole dancing (and thus recreational pole dancers). The framing of recreational pole dancing as neutral with regards to feminist politics, by virtue of the contextual discourse of 'fun and fitness', serves to construct pole dancing in dichotomous terms ('professional' vs. 'fun/fitness'). This construction leaves little room for criticism of the 'fun/fitness' version and simultaneously achieves the construction of two subject positions. Firstly, it positions the woman who chooses to pole dance for fitness as empowered and beyond criticism on account of her participating in an 
activity that is constructed as empowering through the attainment of fun, fitness and hence feeling 'good about [herself]' (line 632). Secondly, the polarized and dichotomous comparisons between recreational and professional pole dancing simultaneously construct those who might seek to question pole dancing (on ideological grounds) as in some way misguided or illinformed. In Extract 1, Alice draws direct comparisons between 'disempowering' professional pole dancing and 'empowering' recreational pole dancing. Through this comparison, anyone who would seek to represent recreational pole dancing as disempowering is thus potentially positioned as confusing the issues surrounding this dichotomous construction.

The following extract provides another example of the invocation of the 'fun and fitness' discourse.

\section{Extract 2: One-Time Semi-Structured Interview 2}

190 Int: $\quad$ So so leading on from that actually (.) what do you think (.) like what would 191 you say to someone who said to you that pole dancing (.) not just 192 professionally but learning it like this is degrading to women?

193 Helen: No way.

194 Int: No?

195 Helen: Nah (.) no way (.) not degrading at all (.) it's fun. It's something different and 196 it's a bit of fun and (.) there's nothing wrong with having a bit of fun (h).

197 Int: Yeah so (.) okay what about if they said it the other way? What if they said that 198 it's empowering?

199 Helen: A::h (.) yeah (h) (.) yeah it is (.) it's um (0.5) yeah it's sort of like (.) it's sort of $200 \quad$ like artistic sort of thing (.) it's like dancing it's just like any normal dancing (.) 201 but you (.) there's a pole involved. Its (.) it takes a lot of skill and (.) confidence 202 203 and um (.) not everyone can do it.

Helen utilizes the fun/fitness discourse to negate arguments potentially leveled against recreational pole dancing, but in a different way to that employed by Alice. Firstly, the 
questioning by the interviewer as to whether recreational pole dancing is potentially degrading is met with a very emphatic denial of such an accusation, one supported by the construction of it as 'fun' (line 195). In this way, pole dancing is constructed as not possibly degrading because it is fun. This draws on the commonsense understanding that anything that is fun must also be a positive experience. However, the most pivotal part of this extract is the use of the phrase 'there's nothing wrong with having a bit of fun (h)' (line 196). In Extract 1, Alice invoked the fun/fitness discourse to contextualize pole dancing in direct contrast with sexual objectification. However, Helen's statement instead invokes the commonsense assumption that 'fun' is a positive, desirable experience that we should all be allowed to gain access to. This functions as a 'rhetorically selfsufficient' argument (Augoustinos, Lecouteur \& Soyland, 2002; Wetherell \& Potter, 1992) in the sense that it closes down opportunity for debate by discursively locating anyone who is against recreational pole dancing as someone who is, by implication, against (women) having fun. Thus, through the invocation of the commonsense assumption of 'fun' as positive, it becomes difficult to question or problematize recreational pole dancing. Additionally, by constructing pole dancing as '...like dancing...just like any normal dancing' (line 201), Helen normalizes the act of pole dancing in such a way as to make it seem ridiculous to represent pole dancing as a possibly disempowering act. Helen then supports this assertion by constructing recreational pole dancing as empowering by virtue of it providing an opportunity for artistic expression (line 201) and the acquisition of skill and confidence (line 202).

\section{Control of choice and money}

The issues of empowerment and disempowerment as related to both recreational and professional pole dancing were most commonly located within a discourse of control regarding 
money and choice. As demonstrated in the following extract, this discourse again serves to construct the actual act of pole dancing as a neutral activity, with the assumptions regarding 'empowerment' moderated, in this case, by control. Moreover, this control was operationalized through the direction of monetary exchange.

\section{Extract 3: Student Focus Group 1}

847 Sally: I think where you draw the line (.) there is probably where the money is 848 (.) like (.) if you're being paid to do it then it's like (.) you have (.) your material)) if you're paying for it (.) if you're paying to go there and [do it]

Int: [Yep]

Sally: [and] its like (.) for yourself and if you (.) like if (.) like for a hens night or something like that where you're paying for it then its (.) the powers kind of with you (.) it's kind of who has the money is the one that's

controlling (.) the (1.0) intent

Int: Yeah yeah [definitely]

Angie: $[\mathrm{M}: \mathrm{m}]$

Sally: [So I think] (.) if (.) if you go in to to do it and you're paying money to do it it's like (.) I want this and it's ok (.) but if you're getting paid to do it (.) it's kind of like (.) you know (.) that's when it's a bit degrading.

When questioned about issues of empowerment and disempowerment, Sally invokes the direction of monetary exchange as the factor that delineates between an 'empowering' and 'disempowering' position (line 847). Sally's reference to 'drawing the line... where the money is' constructs a particular version of social reality in which everything of an empowering nature resides on one side of the aforementioned 'line' and everything of a disempowering nature resides on the other. Here, the sole determinant of what falls on each side of such a line is determined by who is the consumer and who is providing a service. Again, this serves to construct pole dancing as an activity that is politically neutral and, in this instance, contextualized by monetary exchange, control and choice. Sally then states that 'if you're being paid to do it then it's like (.) you have (.) your (.) like your choice has been taken away' (line 
849). Here, Sally constructs the imaginary female subject as being disempowered on the grounds that she has not chosen to give her power away, but has rather had it taken away by an outside agent. Additionally, by stating here that 'you're the one (.) you know (.) that's working for it' (line 850), the participant makes reference to choice being 'taken' away'. Here, it is the presumed male spectator who has 'control of the intent' to receive a pole dance through the expenditure of money, thus commodifying the constructed subject as a sexual item. This is because she must perform, as a requirement of her profession and for the money she needs and, thus, is understood as powerless to resist or to say no.

In contrast, the participant states that when you're paying for pole dancing lessons 'the power's kind of with you (.) it's kind of who has the money is the one that's controlling (.) the (1.0) intent' (line 855). The participant does not clarify what 'the intent' is, but it is constructed as an important issue. Here, control of the intent is contextualized through the direction of monetary exchange in the service relationship, which then denotes where power is presumed to reside. Control of intent to receive pole dancing lessons through the expenditure of money is seen as exercising choice through the attainment of a consumable item that satisfies want. The female subject is constructed as powerful, by virtue of her exercising choice and action. The participant finishes this statement by saying 'but if you're getting paid to do it (.) it's kind of like (.) you know (.) that's when it's a bit degrading' (line 862), presumably as a result of having 'your choice taken away'. Additionally, the construction of professional pole dancing as being 'a bit degrading' (emphasis added) leaves discursive 'space' for a construction of context that perhaps could render it at least neutral, if not empowering.

The construction of the 'paid' vs. 'paying' dichotomy positions women who pole dance for fun as empowered through choice and control of intent, moderated by monetary exchange. In 
this specific instance, this is achieved through the act of consumerism, which can be considered in and of itself an indicator of power through its designation of social status and the ability to expend monetary resources on items that may be considered frivolous. It is worth noting here that this construction serves to reiterate wider cultural discourses of women as consumers and as being empowered by consumerism (Orbach, 1978, 1986). Additionally, consuming this particular 'item' is arguably indicative of adherence to raunch culture, which asserts that an exhibitive, assertive female sexuality is desirable and empowering.

\section{Performance and the male gaze}

Participants also constructed the activity of pole dancing as being inherently performative, where the ideological outlook of the assumed audience is often invoked as a signifier of whether pole dancing should be regarded as empowering or disempowering. As demonstrated in the following extract, discourses relating to the male gaze served to construct the activity of pole dancing as rewarding, by virtue of external appreciation for the performance of the pole dance. However, the presumed variability in the nature of the 'appreciation' on offer in different contexts worked, once again, to construct the otherwise 'neutral' activity in different ideological lights.

\section{Extract 4: Pole Dancing Focus Group 1}

733 Int: $\quad$ Ok (.) cool (.) so do you (.) do you guys think that performing for a stranger

734 would be significantly different from performing for someone you love? Or $735 \quad$ care about?

736 Rachael: [Yep]

737 Sara: [Yeah]

738 Naomi: [Yeah]

739 Michelle: [Yeah]

740 Int: [Yeah?] So why's that?

741 Michelle: Um (.) I dunno (.) I think there's [a certain]

742 Sara: [If it's] with a stranger (.) you would (.) you'd see it more as a joke 
743 Michelle: there's a disconnection there (?) (.) like (.) yeah when it's with someone you $744 \quad$ love (.) you know (.) you're kind of (.) doing it for them (.) kind of

745 Rachael: Oh well it's emotional

746 Michelle: Yeah (.) there's an emotional connection [there]

747 Rachael: [it's more] than just a body (?) whereas if it's a stranger (.) they're in a

$748 \quad$ position where (.) they don't know [you (?)]

749 Michelle: [Yeah]

750 Rachael: they can easily objectify you and just go 'this is a body (.) this is (0.5) cool (.)

751 'tits in my face' whatever (.) whereas (.) when it's someone you love (.) they're

752 gunna see you as 'wow (.) she cares about me this much that she's willing to

753 do this and (.) oh my god (.) look at her confidence' they'll see the other

$754 \quad$ factors as well?

755 Int: $\quad$ Yep (.) [so]

756 Sara: [Yeah they] know the person behind the body

Whilst limitations of space prevent us from reproducing a longer extract from the focus group here, it is important to note (lest we be accused of importing assumptions of normative heterosexuality (Braun 2000)) that in the preceding discussion, the speakers above had selfidentified as heterosexual. In Extract 4 the group members discuss the difference between performing a pole dance for a 'loved one' (in this case, previously denoted as a male partner) and performing for a 'stranger'. Michelle offers an interesting construction of this difference when she suggests that the difference resides in the extent to which a pole dance for a loved one would be done "for them [him]" (line 744). Undoubtedly, when a professional pole dancer dances for a male patron, she is 'doing it for him' (in some sense) because she has been paid to do so in a way that pleases the client. However, when performed for a loved one, the lack of monetary exchange becomes, in Michelle's account, a warrant for framing the act as one of personal choice. The pole dance is done 'for' the partner presumably because the performer wants and chooses to do so. This choice is then conceptualized as 'emotional' (line 745) and as facilitated by the 'emotional connection' (line 746) that exists between two people in the context of an intimate heterosexual relationship. Rachael then takes up this idea, further discussing the perceived difference by constructing the stranger as able to 'easily objectify you' (line 749). Here, Rachael 
states that the stranger could perceive the dancer as 'this is a body (.) this is (0.5) cool (.) tit's in my face' (line 750). Thus, the woman who pole dances for a stranger is constructed as being disempowered, by default, on account of the objectifying male gaze of a stranger. Rachael then contrasts this with the 'loved one', whose hypothetical response to such a performance is constructed (through reported speech) as being 'wow (.) she cares about me this much that she's willing to do this and (.) oh my god (.) look at her confidence' (line 753). What is interesting about these two constructions is the extent to which the social institution of the intimate heterosexual relationship is invoked as an automatic 'antidote' to any suggestion that gendered power may be at play. The implication of the rhetoric presented here is that if a woman is 'willing to do this' 'for him' because she 'cares about him' 'this much', then there can be no possible reason to question whether there is anything potentially problematic about whatever 'this' is, from a gender politics point of view (in this case, performing a pole dance). When thought about in this way, one can begin to see how the end point of such an argument may have potentially damaging results for the position of women in society. If nothing else, it provides male members of heterosexual relationships with the ultimate rhetorical device by which to justify, legitimate and maintain potentially sexist practices, namely: "It's okay for me to objectify her...because I love her". The flexible construction of the nature of the male gaze is further exemplified in extract 5 .

\section{Extract 5 One-Time Semi-Structured Interview 1}

128 Bree: Um I just see it (.) just thought that it was kind of cool that you can kind of use 129 (.) um strength and your body to do something that looks totally amazing (.) which guys think is totally hot so (.) as opposed to (.) you know walking around in a pair (.) like (.) of like you know sexy underwear (.) you can say hey check out what I can do so it's something you can (.) you've actually worked hard at (.) it's something that you've (.) you know put a lot of time and effort into cos it wasn't easy (.) um to have a skill that is kind of like 135

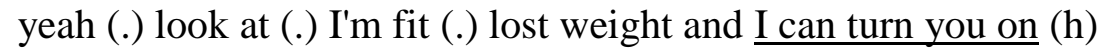


136 Int: (laughter)

137 Bree: (h) so yeah (.) that's kinda why I think it was kinda liberating.

In Extract 5, the participant also speaks about pole dancing as performance. To begin, Bree constructs pole dancing as a performance of 'skill' (line 134) and 'hard work' (line 133). This construction is then immediately juxtaposed against the act of 'walking around in a pair...of...sexy underwear' (line 130). The distinction that is set up between these two acts, both of which could be labeled 'performative', is one of an active/passive binary. That is, Bree sets up a contrast between a 'passive' female sexuality (walking around in sexy underwear) and an 'assertive' female sexuality that is characterized by the ability to perform a 'skill' by virtue of bodily strength. It should be noted here though that this representation of a more 'assertive' female sexuality still positions the female body as the erotic object, through reference to what 'guys think is totally hot' (line 130) and the ability of the performance to 'turn on' a male (line $135)$.

In addition to this, the participant constructs pole dancing as being rewarding to the would-be pupil because of its ability to facilitate conformity to dominant societal ideals of the feminine - 'I'm fit, lost weight and I can turn you on' (line 135). This quote reinforces ideals of femininity as revolving around body size, composition, and the ability to arouse male sexual interest. The participant closes the statement by indicating that this three-part list embodies the reason that she sees pole dancing as 'kinda liberating' (line 137). Thus, it can be argued that the participant constructs liberation as being achieved through an activity that allows a woman to conform to several different dominant societal scripts of femininity at the same time (losing weight, being toned, attracting male interest, and pleasing a male spectator). This is coupled with the constructed ability to resist stereotypes of passive, servile feminine sexuality with a more assertive female sexuality. 


\section{DISCUSSION}

The theme that runs through all three discursive constructions of pole dancing reported above revolves around issues of choice and control. As demonstrated in our analysis section, the fun/fitness discourse discursively locates the choice to take up recreational pole dancing as empowering through the attainment of fun and fitness. This is directly contrasted with professional pole dancing, where choice and empowerment are implicitly constructed as missing by virtue of the experience of sexual objectification. Moreover, the invocation of the fun/fitness discourse serves as a rhetorical device utilized to head off potential criticism by positioning those who would question recreational pole dancing as somewhat misinformed and as someone who would deny women the right to have 'fun'.

The control of money and choice discourse is a more explicit reference to the subject of control. Here, control and choice are specifically moderated by money, which was constructed as providing consumerist power in response to want. This is again juxtaposed with professional pole dancing, which was constructed by our participants as disempowering by virtue of the professional dancer being required to be objectified and sell herself to make money, rather than expend it on items that she wants. Thus, women who participate in recreational pole dancing are constructed as empowered through their ability to exercise consumerist power.

The discourse of performance and the male gaze represents a more implicit reference to choice and control. Here, the female subject is constructed as empowered through her access to control and choice as to when she positions herself as the erotic object. Unlike the professional pole dancer who must dance for her patron because she has been 'bought' as a sexual item, the recreational pole dancer is constructed as having control and choice due to the being the consumer in the exchange (rather than service provider) and the discursive redefinition of the 
male gaze of 'loved ones' as 'appreciative' , rather than 'objectifying'. Additionally, pole dancing was also constructed as liberating on account of its ability to facilitate a woman's obtainment of control over body size and shape so as to conform to societal expectations of desirable femininity.

As argued in the introduction, recreational pole dancing does not represent the pornographic in the most technical sense. However, the issues which arise from feminist debates about the status of pornography are undeniably relevant, particularly those relating to patriarchal power structures, gender stereotypes, objectification, sexual expression, individual choice and the freedom to resist prevailing political and societal traditions. Some liberal feminist arguments would consider the choice to consume or participate in some forms of 'pornography', as a means of societal resistance, a basic human freedom that everyone should have access to. As we have demonstrated throughout our analysis, control and choice were repeatedly invoked as central to the participants' accounts. Within these accounts, pole dancing was constructed by participants as providing a space for women to actively resist dominant patriarchal notions of feminine sexuality.

However, one could argue that our participants' accounts may also potentially work to reinforce elements of a sexist social order, as demonstrated by the performance and the male gaze discourse. The 'benefits' of partaking in pole dancing for recreation were often constructed around its ability to help women conform to body/fitness standards related to the 'feminine ideal' and also the construction of the self as an erotic object. In this sense, the burgeoning social institution of recreational pole dancing can be seen as reinforcing wider societal discourses of male sexuality as possessive and consumptive and female sexuality, in contrast, as something to be possessed and consumed. 
It is also of analytic interest that many of the participants in the current research attempted numerous times to construct the act of pole dancing itself as essentially politically neutral, with the ideological palatability of pole dancing as being determined by the context in which the activity was performed. This may work, rhetorically, to disconnect pole dancing from its place of origin (namely, the sex industry). In this way, pole dancing can be redefined and reclaimed as an empowering, fitness activity. One way in which this reclamation was achieved was through the construction of pole dancing as an art form. In this way pole dancing is discursively redefined as no longer a 'seedy' or subculture activity, but as a legitimate form of artistic expression. This is important when considering the popularity of pole dancing at the moment in the cultural and historical context of raunch culture and the pornographication of the mainstream. It is arguable that when pornography or acts considered pornographic do make the 'leap' from subculture to mainstream, it is achieved via art. Thus, pole dancing is able to make the transition from a 'disempowering', 'underground' activity to an 'empowering' 'mainstream' activity via its discursive (re)location as an ideologically neutral activity. Then, once rendered neutral, it is (re)constructed as a form of expression requiring artistic talent, persistence, confidence and as resulting in a skill that is 'just like any normal dancing'.

It is worth noting, however, a potential metholdogical feature of the current research that may have implications for the talk that was produced. A strong attempt was made through our methodology to use open, generalized questions so as not to make our contributors feel uncomfortable or as if their particular practices or identities were being marginalized in the discussions. This may, however, have produced a possible methodological limitation. By asking more directive, probing and challenging questions we perhaps could have created more opportunities for the generation of counter-narratives that positioned accounts in relation to 
broader socio-political discourses (such as 'feminism'). We would acknowledge this potential weakness and suggest that this could be a fruitful angle for future research.

In conclusion, we argue that talk around recreational pole dancing can be seen to attend to a variety of complex and interesting ideological dilemmas. As an individual activity, it can be constructed as empowering through the extent to which it affords women the opportunity to exercise a form of 'choice' and 'control'. It may also provide a vehicle for women to resist hegemonic notions of femininity as passive and modest. However, following Dentith (2004), one must consider that activities experienced as liberating on an individual level may often secure societal-level oppression in covert ways. Thus, pole dancing may reinforce societal notions of both masculine and feminine sexuality as a result of encouraging women to construct themselves as erotic objects.

\section{ACKNOWLEDGEMENTS}

The authors would like to acknowledge Ngaire Donaghue, Mark Summers, Farida Tilbury, Nicola Gavey, as well as 5 anonymous reviewers, all of whom made helpful suggestions on earlier versions of this manuscript.

\section{Notes}

${ }^{1}$ The term 'Hens Night' refers to a celebratory 'girl's night out' that is typically organised just prior to a woman getting married.

\section{REFERENCES}

Attwood, F. (2005). Fashion and passion: Marketing sex to women. Sexualities, 8(4), 392-406. 
Augoustinos, M., Lecouteur, A., \& Soyland, J. (2002). Self-sufficient arguments in political rhetoric: Constructing reconciliation and apologizing to the stolen generations. Discourse \& Society, 13, 105-141.

Braun, V. (in, press). "The women are doing it for themselves": The rhetoric of choice and agency around female genital ‘cosmetic surgery’. Australian Feminist Studies.

Braun, V. (2000). Heterosexism in focus group research: Collusion and challenge. Feminism \& Psychology, 10, 133-140.

Braun, V., \& Gavey, N. (1999). 'Bad girls' and 'Good girls'? Sexuality and cervical cancer. Women's Studies International Forum, 22, 203-213.

Coward, R. (1993). Our treacherous hearts: Why women let men get their way. London: Faber \& Faber.

Davies, B., \& Harre, R. (1990). Positioning: The discursive production of selves.Journal and Theory of Social Behavior, 20, 43-65.

Davis, K. (1995). Reshaping the Female Body: The Dilemma of Cosmetic Surgery. New York: Routledge.

Dentith, A. M. (2004). Female adolescent subjectivities in Las Vegas: Poststructural thoughts on intersections of gender, sexuality, consumer logic and curriculum. Gender and Education, $16,455-471$.

Deville, J. (2006). The art of pole dancing: History of pole dancing. [Online].Available: http://www.dancepages.com.au/articles/view/49

Edley, N., \& Wetherell, M. (2001). Jekyll and Hyde: Men's constructions of feminism and feminists. Feminism \& Psychology, 11, 439-457.

Foucault, M. (1978). The history of sexuality: An Introduction. New York: Vintage Books. 
Gavey, N. (1989). Feminist poststructuralism and discourse analysis: Contributions to feminist psychology. Psychology of Women Quarterly, 13, 459-475.

Gavey, N. (2005). Just Sex?: The Cultural Scaffolding of Rape. London: Routledge

Gill, R. (forthcoming). Supersexualize me!: Advertising and 'the midriffs'. In F. Attwood, R. Brunt \& R. Cere (Eds) Mainstreaming Sex: The Sexualization of Culture. London: I.B. Taurus

Gill, R. (2007b). Critical respect: The difficulties and dilemmas of agency and 'Choice' for feminism. European Journal of Women's Studies, 14, 69-80.

Gill, R. (2008). Empowerment/sexism: Figuring female sexual agency in contemporary advertising. Feminism \& Psychology, 18, 35-60.

Griffin, C. (1989). 'I'm not a women's libber but...': Feminism, consciousness and identity. In S. Skevington \& S. Baker (Eds). The social identity of women.(pp. 173-93). London: Sage. Hughes, Christina. (2002). Key concepts in feminist theory and research. London: Sage.

Keller, J. (2006). Pole dancing is the hot class at UBC. [Online]. Available: http:// thetyee.ca/Life/2006/01/13/PoleDancing/

Lazar, M. (2006). "Discover the power of femininity!": analyzing global 'power femininity' in local advertising. Feminist Media Studies, 6, 505-518.

Levy, A. (2005). Female Chauvinist Pigs: Women and the rise of raunch culture. New York: Schwartz.

Lumby, C. (1997). Bad Girls: The media, sex and feminism in the '90's. St Leonards: Allen \& Unwin Pty Ltd. 
MacKinnon, C. A. (1989). Pornography: Not a moral issue. In D. Spender (Ed). Radical Voices: A decade of feminist resistance from Women's studies international forum. (pp. 143-170). Oxford: Pergamon Press.

Mason-Grant, J. (2004). Pornography Embodied: From speech to sexual practice. Maryland: Rowman \& Littlefield Publishers.

McNair, B. (2002). Striptease Culture: Sex, media and the democratization of desire. London: Routledge.

McNay, L. (1992). Foucault and feminism. Cambridge: Polity Press.

Morgan, K. (1991). Woman and the knife: Cosmetic surgery and the colonization of women's bodies. Hypatia, 6, 25-53.

Murphy, A. G. (2003). The Dialectical Gaze: Exploring the subject-object tension in the performance of women who strip. Journal of Contemporary Ethnography, 32, 305-335.

Orbach, S. (1978). Fat is a feminist issue: The anti-diet guide to permanent weight loss. $\left(^{\text {nd }}\right.$ Ed). London: Paddington Press Ltd.

Orbach, S. (1986). Hunger strike. ( ${ }^{\text {st }}$ Ed) Suffolk: Richard Clay Ltd.

Parker, I. (1994). Reflexive research and the grounding of analysis: Social psychology and the psy-complex. Journal of Community and Applied Social Psychology, 4, 239-252.

Peace, P. (2003). Balancing power: The discursive maintenance of gender inequality by Wo/Men at University. Feminism and Psychology, 13, 159-180.

Pitcher, K.C. The staging of agency in girls gone wild. Critical Studies in Media Communication, 23(3), 200-218.

Potter, J., \& Wetherall, M. (1987). Discourse and Social Psychology: Beyond attitudes and behaviour. London: Sage. 
Reeve, S. (2007). The history of pole dancing. [Online]. Available: http://www. Polefitness.co.nz/thehistory.htm

Renzetti, C. M. (1987). New wave or second stage? Attitudes of college women towards feminism. Sex Roles, 16, 265-277.

Riley, S. (2001). Maintaining Power: Male constructions of 'feminists' and 'feminist values'. Feminism and Psychology, 11, 55-78.

Schauer, T. (2005). Women's Porno: The heterosexual female gaze in porn sites 'for women'. Sexuality and Culture, 9, 42-64.

Scott, L. (2005). Fresh lipstick: Redressing fashion and feminism. New York: Palgrave.

Segal, L. (1998). Only the literal: The contradictions of anti-pornography feminism. Sexualities, 1, 43-62.

Weatherall, A., Gavey, N., \& Potts, A. (2002). So whose words are they anyway? Feminism \& Pychology, 12, 533-541.

Wetherell, M. (1998). Positioning and interpretative repertoires: conversation analysis and poststructuralism in dialog. Discourse and Society, 9, 387-412.

Wetherall, M., \& Potter, J. (1992). Mapping the language of racism: Discourse and the legitimation of exploitation. New York: Columbia University Press.

Whelehan, I (1995). Modern feminist thought: From second-wave to 'post-feminism' Edinburgh: Edinburgh University Press.

Whelehan, I. (2000). Overloaded: Popular culture and the future of feminism. London: The Women's Press.

Willig, C. (2001). Introducing Qualitative Research in Psychology: Adventures in theory and method. Buckingham: Open University Press. 
APPENDIX: Transcription Notation Used

Underline for emphasis

CAPITALS - words spoken more loudly than surrounding talk

$\underline{\text { Underline }}$ - denotes emphasis on word/syllable

(.) - micropause, shorter than half a second

(0.5) - for pauses 0.5 seconds or longer

[overlap] - contains overlapping talk

(?) - rising or questioning intonation

(h) laughter within speech

lo:ng - elongation of prior sound

$(($ text $))$ - text added by the researcher, such as describing actions etc

<indiscernible> - unclear recording, unable to transcribe.

Kally Whitehead is a PhD candidate in the School of Psychology at Murdoch University in Western Australia. Her research interests lie in the social construction of gender, with specific focus on female body image and sexuality in the context of contemporary 'raunch culture'.

Tim Kurz is a lecturer in the School of Psychology at Murdoch University. His research interests include the social construction of gender and social psychological aspects of environmental sustainability. 
ADDRESS: School of Psychology, Murdoch University, South Street, Murdoch, W.A, 6150, AUSTRALIA.

[email t.kurz@murdoch.edu.au] 